\title{
SELECTION OF REFERENCE PLANE BY THE LEAST SQUARES FITTING METHODS
}

\author{
Przemysław Podulka ${ }^{1}$ \\ 1 The Faculty of Mechanical Engineering and Aeronautics, Rzeszow University of Technology, Powstańców \\ Warszawy 8, 35-959 Rzeszów, Poland, e-mail: przpod@prz.edu.pl
}

Received: 2016.03.25

Accepted: 2016.05.10

Published: 2016.06.01

\begin{abstract}
There are many disadvantages affecting the accuracy of surface topography measurement and analysis. One of them are the errors obtained during data processing. Usually surface topographies of car engine parts are studied after form removal. Many algorithms and procedures were developed and suggested. However, the selection of reference plane with accordance to surface topography measurements of cylindrical elements was not fully recognized. In this paper least square fitting methods (cylinder, polynomial) and commercial filters (Gaussian filter, Gaussian regression filter and robust Gaussian regression filter) for areal form removal were compared and proposed. Three types of surfaces: cylinder liners after plateau-honing, plateau-honed cylinder liners with oil pockets created by burnishing techniques and turned piston skirts were analyzed. Distortion of surface topography parameters (from ISO 25178 standard) according to improper selection of reference plane was also taken into consideration. It was assumed that least squares fitted cylinder plane gave better results for both of type cylinder liners according to commonly used algorithm. However, for piston skirt surfaces the obtained results were very similar. For least squares polynomial fittings it was found that applied method for cylinder liners gave usually better robustness for scratches, valleys and dimples occurrence. For piston skirt surfaces better edgefiltering results were obtained. It was also recommended to analyse the Sk parameters for proper selection of reference plane in surface topography measurements.
\end{abstract}

Keywords: surface topography, reference plane, least squares fitting, cylinder fitting, polynomial approximation, oil pockets, cylinder liners, piston skirts.

\section{INTRODUCTION}

There are the following kinds of measurement uncertainty: errors typical for the measuring method [17, 21], errors caused by the digitisation process, errors obtained during data processing [9] and other errors [19]. Errors typical for surface topography measurement using a stylus instrument were described in [16]. Surface topography parameters are usually calculated afterwards form removal as a data evaluation process. There were many algorithms created and used for extraction of surface texture properties. However, not many research concerns the influence of reference plane on the values of surface topography parameters [19].
Examples of filters encountered in surface topography measurement systems include mechanical, electrical and digital filtering [24]. For car engine cylinder liners and piston skirts, evaluation of reference plane was often proposed by: cylinder fittings $[8,19]$, polynomial approximations $[3,9,19,24]$, plenty Gaussian filtering procedures (Gaussian filters [1, 4, 10, 13, 25, 27, 28], regression algorithms $[1,2,4,13]$, robust filtering $[1,5,6,13,18,23])$, spline filters $[4,13,29]$, morphological methods $[11,13]$, wavelet decompositions [3, 13] and others [12, 13, 24].

One of the commonly used method is fitting a plane with geometrical shape. It was proposed to fit the cylinder plane by the least square methods $[8,13,21]$. It was found, that the application of 
cylinder form removal by commercial software did not allow to select a reference plane correctly [19]. The surface curvature was notfully removed and parameters were falsely estimated.

In many research papers polynomial approximation was recommended $[3,7,19,26]$. There were the following degrees of polynomials suggested: $2^{\text {nd }}[11,24], 3^{\text {rd }}[19], 4^{\text {th }}[23]$ or higher $\left(6^{\text {th }}-8^{\text {th }}[19]\right)$. The degree of polynomials was proposed for each type of surface [25]. The $2^{\text {nd }}$ and $3^{\text {rd }}$ degree was selected for plateau-honed cylinder liners with additionally burnished oil pockets, $3^{\text {rd }}$ or $4^{\text {th }}$ for cylinder liners after plateau-honing and turned piston skirts. It was shown that higher (more than $4^{\text {th }}$ ) degree of the polynomial caused a dissertation of surface topography parameters. However, for piston skirt surfaces containing the curvatures, it was noticed, that using the $4^{\text {th }}$ degree of polynomial was not a good solution. Therefore, the polynomials from 6th to 8th degree were recommended [19]. The change of the rough core Sk is interesting, especially for cylinder surfaces containing deep and wide valleys. Initially during an increase of the polynomial degree the Sk parameter decreased [19]. Improper estimation of Sk parameters is of great importance. It was found that oil emission by the engine was proportional to the core roughness Sk and cylinder wear under various conditions was proportional to the emptiness coefficient $\mathrm{Sp} / \mathrm{Sz}[14,15]$. Improper selection of reference planes can also cause wrong estimation of dimple sizes [9].
The least square fitting of reference plane was clearly presented in $[7,8,12,13]$. Many algorithms for optimisation were also applied and approved $[7,8]$. In this paper, the least square fittings of cylinder and polynomials were presented and compared with generally used procedures. For selection of reference plane the Gaussian filter, Gaussian regression filter and robust Gaussian regression filter were also used and confirmed.

\section{MATERIALS AND METHODS}

In this paper three types of surfaces were analysed: cylinder liners after plateau-honing process (example in Figure 1a and 1d), plateauhoned cylinder liners with oil pockets created by burnishing techniques (Figure $1 \mathrm{~b}$ and $1 \mathrm{e}$ ) and turned piston skirts (see Figure 1c and 1f). More than 30 surfaces were analysed. They were measured by Talyscan 150 stylus equipment (nominal tip radius about $2 \mu \mathrm{m}$, height resolution about 10 $\mathrm{nm}$ ) and white light interferometer Talysurf CCI Lite with height resolution $0.01 \mathrm{~nm}$.

Two types of the least square algorithms were proposed: cylinder and polynomial fittings. Algorithms were created in Matlab environment (The MathWorks, Inc.).

The parameters from ISO 25178 standard were analysed (such as: root mean square height Sq, skewness Ssk, kurtosis Sku, maximum surface peak height $\mathrm{Sp}$, maximum valley a)

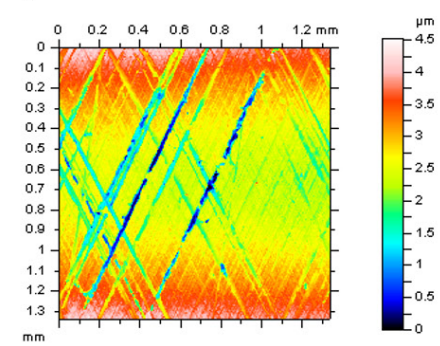

d)

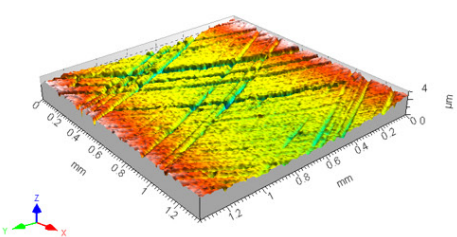

b)

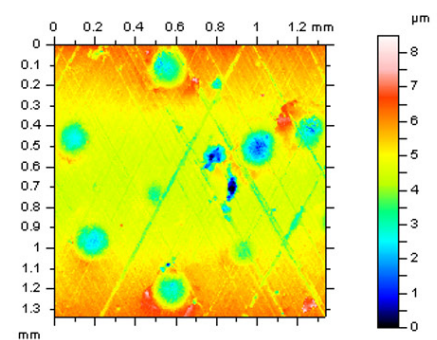

e)

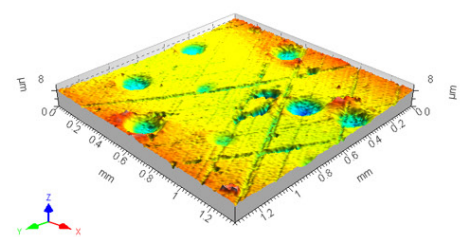

c)

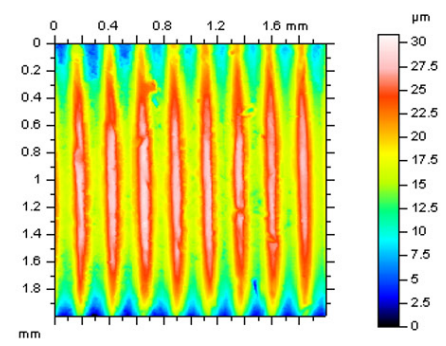

f)

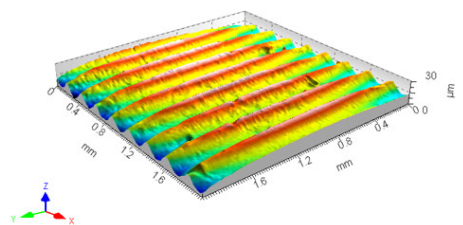

Fig. 1. Contour plots (a, b and c) and isometric views (d, e and $f$ ) of measured surface of: cylinder liner after plateau-honing process (a, d), plateau-honed cylinder liner with additionally burnished oil pockets $(b, e)$ and turned piston skirt $(\mathrm{c}, \mathrm{f})$ 
depth Sv, maximum height Sz, arithmetic mean height Sa, auto-correlation length Sal, texture-aspect ratio Str, texture direction Std, root mean square slope Sdq, interfacial area ratio Sdr, summit density Spd, arithmetic mean peak curvature Spc) with particular attention to Sk group parameters (reduced summit height Spk, reduced valley depth Svk, core roughness depth Sk, upper bearing area $\mathrm{Sr} 1$ and lower bearing area $\mathrm{Sr} 2$ ).

\section{LEAST SQUARE FITTING ALGORITHMS FOR THE REFERENCE PLANE SELECTION}

For selection of reference plane two least square fitting procedures were proposed. Firstly, the algorithm of cylinder fitting was created and applied. Secondly, the polynomial least square fitted plane of $n$-th order was recommended. In this part the mathematical aspects of suggested procedures were presented.

\section{Cylinder fitting by the least square method}

For functional textures, form elimination seems to be a better alternative to digital filtration [19]. One of the form removal method is the least square fitting a cylinder plane $[8,21]$.

The cylinder plane is defined by $[8,13]$ :

- a points $\left(\mathrm{x}_{\mathrm{o}}, \mathrm{y}_{\mathrm{o}}, \mathrm{z}_{\mathrm{o}}\right)$ on the axis,

- a vector $(\mathrm{a}, \mathrm{b}, \mathrm{c})$ pointing along the axis and its radius $\mathrm{r}$.

For fitting process, the distance from a point $\left(\mathrm{x}_{\mathrm{i}}, \mathrm{y}_{\mathrm{i}}, \mathrm{z}_{\mathrm{i}}\right)$ to a cylinder need to be found. It is defined as [8]:

$$
d_{i}=r_{i}-r
$$

where:

$$
r_{i}=\frac{\sqrt{u(i)^{2}+v(i)^{2}+w(i)^{2}}}{\sqrt{a^{2}+b^{2}+c^{2}}}
$$

with:

$$
\begin{aligned}
u(i) & =c\left(y(i)-y_{c}\right)-b\left(z(i)-z_{c}\right) \\
v(i) & =a\left(z(i)-z_{c}\right)-c\left(x(i)-x_{c}\right) \\
w(i) & =b\left(x(i)-x_{c}\right)-a\left(y(i)-y_{c}\right)
\end{aligned}
$$

The objective function is given by [13]:

$$
E=\sum_{i=1}^{n} d(i)^{2}
$$

Than the objective function is linearized to:

$$
\begin{array}{r}
d(i)=R_{0}(i)-r_{0}+\left(x_{c 1}-x_{c 0}\right) \frac{\partial d(i)}{\partial x_{c 0}}+\left(y_{c 1}-y_{c 0}\right) \frac{\partial d(i)}{\partial y_{c 0}}+\left(z_{c 1}-z_{c 0}\right) \frac{\partial d(i)}{\partial z_{c 0}} \\
=\left(a_{1}-a_{0}\right) \frac{\partial d(i)}{\partial a_{0}}+\left(b_{1}-b_{0}\right) \frac{\partial d(i)}{\partial b_{0}}+\left(c_{1}-c_{0}\right) \frac{\partial d(i)}{\partial c_{0}}+\left(r_{1}-r_{0}\right) \frac{\partial d(i)}{\partial r_{0}}
\end{array}
$$

and solve the resulting system of $\mathrm{n}$ equations in seven variables expressed in the form $\mathrm{JP}=-\mathrm{D}$ or $\left(\mathrm{J}^{\mathrm{T}} \mathrm{J}+\lambda \mathrm{R}^{\mathrm{T}} \mathrm{R}\right) \mathrm{P}=-\mathrm{J}^{\mathrm{T}} \mathrm{D}$, as the case may be [13]. The matrices $\mathrm{J}, \mathrm{P}$, and $\mathrm{D}$ are given by:

$$
J=\left[\begin{array}{ccccccc}
\frac{\partial d(1)}{\partial x_{c o}} & \frac{\partial d(1)}{\partial y_{c o}} & \frac{\partial d(1)}{\partial z_{c o}} & \frac{\partial d(1)}{\partial a_{0}} & \frac{\partial d(1)}{\partial b_{0}} & \frac{\partial d(1)}{\partial c_{0}} & \frac{\partial d(1)}{\partial r_{0}} \\
\cdots & \cdots & \cdots & \cdots & \cdots & \cdots & \cdots \\
\frac{\partial d(n)}{\partial x_{c o}} & \frac{\partial d(n)}{\partial y_{c o}} & \frac{\partial d(n)}{\partial z_{c o}} & \frac{\partial d(n)}{\partial a_{o}} & \frac{\partial d(n)}{\partial b_{o}} & \frac{\partial d(n)}{\partial c_{o}} & \frac{\partial d(n)}{\partial r_{o}}
\end{array}\right]
$$




$$
\begin{gathered}
P=\left[\begin{array}{c}
\left(x_{c 1}-x_{c o}\right) \\
\left(y_{c 1}-y_{c o}\right) \\
\left(z_{c 1}-z_{c o}\right) \\
\left(a_{1}-a_{o}\right) \\
\left(b_{1}-b_{o}\right) \\
\left(c_{1}-c_{o}\right) \\
\left(r_{1}-r_{o}\right)
\end{array}\right] \\
D=\left[\begin{array}{c}
d(1) \\
\ldots \\
d(n)
\end{array}\right]
\end{gathered}
$$

The optimization process is usually given by Gauss-Newton algorithm [7, 8].

\section{Least square fitted polynomial plane of $\mathrm{n}$-th order}

The least square $n$-th order polynomial surface is expressed as [24]:

$$
f(x, y)=\sum_{i=0}^{n} \sum_{j=0}^{i} a_{(i-j) j} x^{i-j} y^{j}
$$

For example a second order quadratic polynomial surface [23] would involve all the items of the first three columns of Table 1, that is:

$$
f(x, y)=a_{00}+a_{10} x+a_{01} y+a_{20} x^{2}+a_{11} x y+a_{02} y^{2}
$$

The sum of the surface asperity departures from this polynomial plane was given by [24]:

$$
\varepsilon^{2}=\sum_{l=1}^{N} \sum_{k=1}^{M}\left(z\left(x_{k}, y_{l}\right)-f\left(x_{k}, y_{l}\right)\right)^{2}=\sum_{l=1}^{N} \sum_{k=1}^{M}\left(z\left(x_{k}, y_{l}\right)-\sum_{i=0}^{n} \sum_{j=0}^{i} a_{(i-j) j} x_{k}^{i-j} y_{l}^{j}\right)^{2}
$$

For simplicity of analysis, that was assumed:

$$
\mathrm{q}_{\mathrm{p}}=\mathrm{z}\left(\mathrm{x}_{\mathrm{k}}, \mathrm{y}_{\mathrm{l}}\right), \quad \mathrm{g}_{\mathrm{p}}=\mathrm{f}\left(\mathrm{x}_{\mathrm{k}}, \mathrm{y}_{\mathrm{l}}\right), \quad \mathrm{u}_{\mathrm{p}}=\mathrm{x}_{(\mathrm{p}-[\mathrm{p} / \mathrm{M}] \cdot \mathrm{M})}=\mathrm{x}_{\mathrm{k}}, \quad v_{\mathrm{p}}=\mathrm{y}_{[\mathrm{p} / \mathrm{M}+1]}=\mathrm{y}_{\mathrm{l}}
$$

where: $\mathrm{p}=(1-1) \mathrm{M}+\mathrm{k}$ and [.] means that the integer part of the result was taken.

Thus, the final result from equation (13) was rewritten as [24]:

$$
\varepsilon^{2}=\sum_{p=1}^{M x N}\left(q_{p}-g_{p}\right)^{2}=\sum_{k=1}^{M x N}\left(q_{p}-\sum_{i=0}^{n} \sum_{j=0}^{i} a_{(i-j) j} u_{p}^{i-j} y_{p}^{j}\right)^{2}
$$

and the normal equations of the least squares problem, was expressed in matrix form as:

$$
[v]^{\mathrm{T}}[v]\{\mathrm{A}\}=[v]^{\mathrm{T}}\{\mathrm{Q}\}
$$

where:

$$
v=\left[\begin{array}{cccccccc}
1 & u_{1} & v_{1} & u_{1}^{2} & u_{1} v_{1} & \ldots & u_{1} v_{1}^{n-1} & v_{1}^{n} \\
1 & u_{2} & v_{2} & u_{2}^{2} & u_{2} v_{2} & \ldots & u_{2} v_{2}^{n-1} & v_{2}^{n} \\
\vdots & \vdots & \vdots & \vdots & \vdots & \ldots & \vdots & \vdots \\
1 & u_{p} & v_{p} & u_{p}^{2} & u_{p} v_{p} & \ldots & u_{p} v_{p}^{n-1} & v_{p}^{n}
\end{array}\right],\{A\}=\left\{\begin{array}{c}
a_{00} \\
a_{10} \\
a_{01} \\
a_{20} \\
a_{11} \\
\vdots \\
a_{1(n-1)} \\
a_{0 n}
\end{array}\right\},\{Q\}=\left\{\begin{array}{c}
q_{1} \\
q_{2} \\
\vdots \\
q_{p}
\end{array}\right\}
$$


Table 1. Elements of polynomial surfaces

\begin{tabular}{|c|c|c|c|c|c|}
\hline \multicolumn{7}{|c|}{$n$} \\
\hline$j=0$ & 1 & $x$ & $x^{2}$ & $x^{3}$ & $x^{4}$ \\
\hline$j=1$ & & $y$ & $x y$ & $x^{2} y$ & $x^{3} y$ \\
\hline$j=2$ & & & $y^{2}$ & $x y^{2}$ & $x^{2} y^{2}$ \\
\hline$j=3$ & & & & $y^{3}$ & $x y^{3}$ \\
\hline$j=4$ & & & & & $y^{4}$ \\
\hline
\end{tabular}

Then the Gauss-Jordan elimination can be easily employed [22] and equation (16) can be solved as the follows:

$$
\{\mathrm{A}\}=\left([v]^{\mathrm{T}}[v]\right)[v]^{\mathrm{T}}\{\mathrm{Q}\}
$$

These two least square procedures were elaborated in Matlab environment and applied for areal form removal in cylinder liner and piston skirt surface analysis.

\section{RESULTS AND DISCUSSIONS}

\section{Cylinder liners after plateau-honing process}

For cylinder liner surfaces after plateau-honing treatment the commonly used algorithm for cylinder form removal did not allow to select the reference plane correctly. The surface curvature was not fully removed (see Figure 2a).

For least square fitted cylinder plane it was found that values of Sk and Spk parameters de- creased while Svk parameter value increased according to generally used algorithm (Figure $2 \mathrm{c}$ and $2 \mathrm{f}$ ). The Sz parameter values has also decreased (Table 2).

For cylinder fitted by proposed procedure, height parameters $\mathrm{Sq}, \mathrm{Sp}, \mathrm{Sv}, \mathrm{Sz}$ as well as $\mathrm{Sa}$ decreased, but skewness Ssk and kurtosis Sku increased according to generally used algorithm.

Spatial parameter texture-aspect ratio Str decreased but auto-correlation length Sal and texture direction Std were not changed as well as hybrid parameters Sdq and Sdr.

For application of polynomial of $4^{\text {th }}$ degree form removal, the difference in Sz parameters value was not found so clearly. However, Sk parameter decrease by about $22 \%$, Spk by about $16 \%$ while Svk parameter increased by around $7 \%$ (Figure 3c and 3f). Moreover, the least square fitting procedure was particularly more robust for valleys and scratches occurrence.

For the proposed procedure, due to generally used algorithm, application of $4^{\text {th }}$ degree of polynomial resulted in an increase of height parameters Sq, Ssk and Sku but decrease of Sp, $\mathrm{Sv}, \mathrm{Sz}$ and Sa parameters. The values of spatial parameter Std was equal but Sal and Str parameters increased. The differences of values of hybrid parameters Sdq and Sdr were not found (see Table 2).

For proposed algorithms (cylinder and polynomial) peak density Spd increased but peak a)

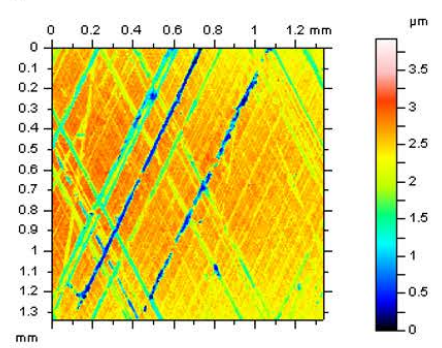

d)

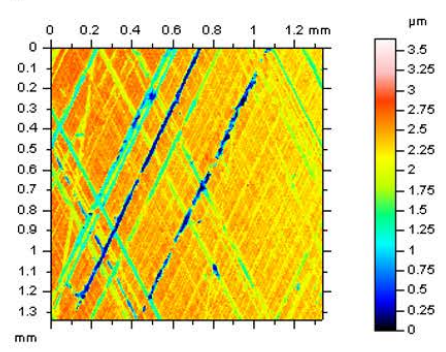

b)

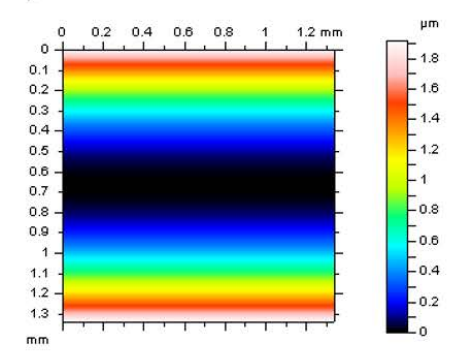

e)

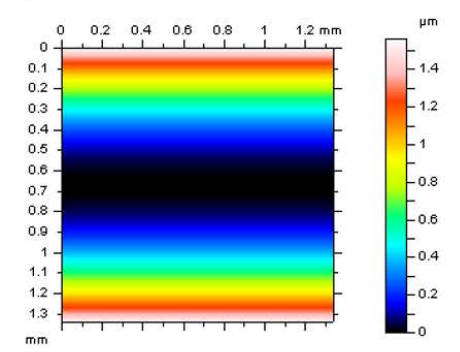

c)

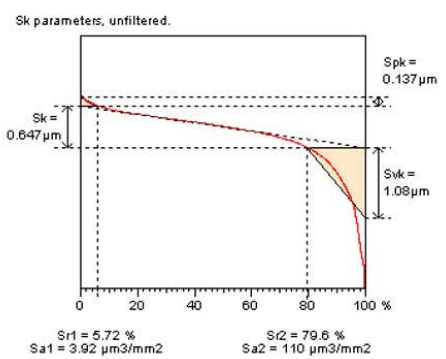

f)

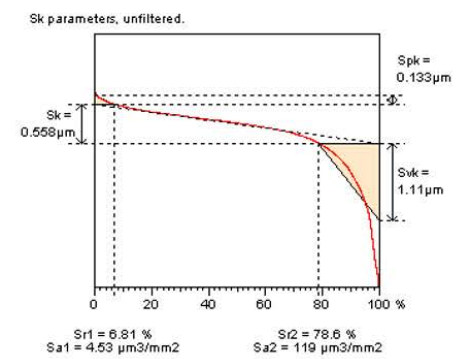

Fig. 2. Contour plots of surface after form removal (a, d); removed form (b, e); material ratio curve (c, f) of plateau-honed cylinder liner after form removal by: generally used cylinder fitting algorithm ( $a, b$ and $c)$, proposed cylinder least squares fitting procedure $(\mathrm{d}$, e and $\mathrm{f}$ ) 
a)

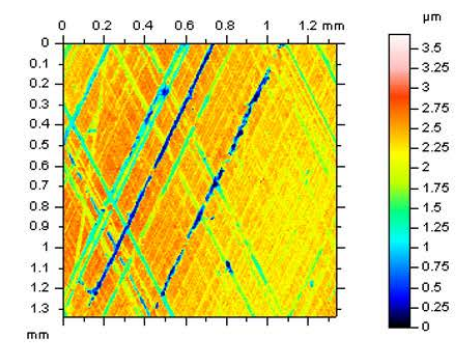

d)

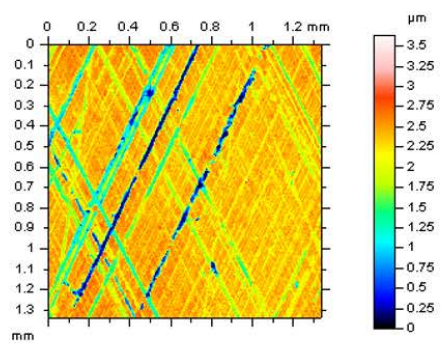

b)

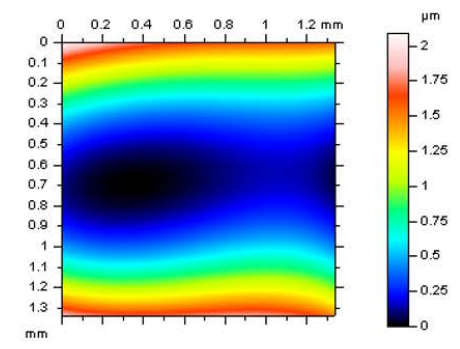

e)

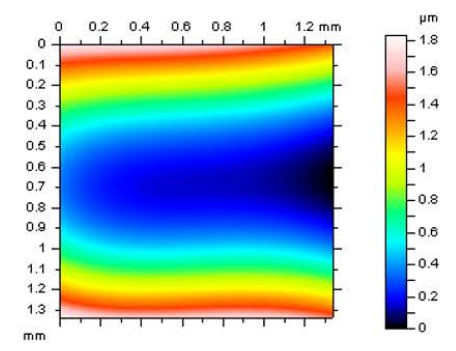

c)

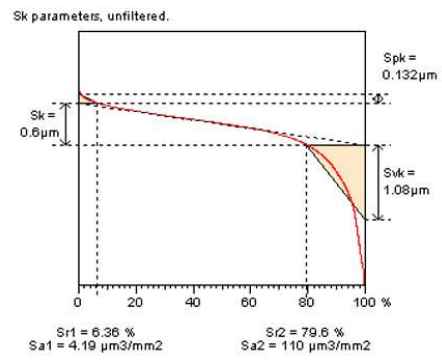

f)

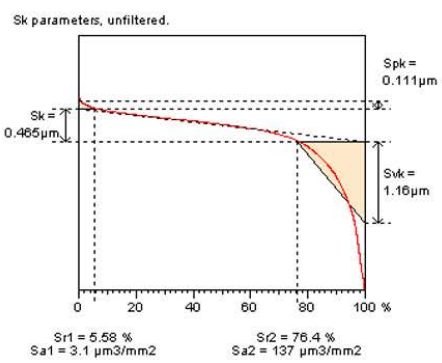

Fig. 3. Contour plots of surface after form removal (a, d); removed form (b, e); material ratio curve (c, f) of cylinder liner after plateau-honing process and after form removal by: generally used 4th degree of polynomial ( $\mathrm{a}, \mathrm{b}$ and $\mathrm{c})$, proposed least squares polynomial fitting procedure (d, e and $\mathrm{f}$ )

curvature Spc decreased and for polynomial approximation differences of Spc parameter were negligible.

Least square fitted cylinder and polynomial planes seem to give more effective solutions for areal form removal of plateau-honed cylinder liners according to generally used algorithms.

\section{Plateau-honed cylinder liners with additionally burnished oil pockets}

Is was noticed that the application of commonly used algorithm for cylinder fitting did not allow to correctly eliminate the form from the results of surface topography measurements of plateau-honed cylinder liners with additionally added oil pockets (see Figure 4a).

Table 2. Surface topography parameters of cylinder liner after plateau-honing for cylinder and polynomial of 4th degree form removal

\begin{tabular}{|c|c|c|c|c|c|c|}
\hline \multirow{3}{*}{\multicolumn{2}{|c|}{ Parameters }} & \multirow{4}{*}{$\begin{array}{c}\begin{array}{c}\text { Measured } \\
\text { surface }\end{array} \\
0.670\end{array}$} & \multicolumn{4}{|c|}{ Surface after form removal using: } \\
\hline & & & \multicolumn{2}{|c|}{ cylinder fitted by: } & \multicolumn{2}{|c|}{ polynomial of $4^{\text {th }}$ degree: } \\
\hline & & & $\begin{array}{l}\text { general } \\
\text { algorithm }\end{array}$ & $\begin{array}{c}\text { proposed } \\
\text { method }\end{array}$ & $\begin{array}{l}\text { commonly } \\
\text { used method }\end{array}$ & $\begin{array}{l}\text { proposed } \\
\text { algorithm }\end{array}$ \\
\hline \multirow{7}{*}{$\begin{array}{l}\text { Height } \\
\text { parameters }\end{array}$} & $\mathrm{Sq}, \mu \mathrm{m}$ & & 0.467 & 0.460 & 0.453 & 0.474 \\
\hline & Ssk & -0.513 & -2.060 & -2.210 & -2.120 & -2.770 \\
\hline & Sku & 4.07 & 8.02 & 8.61 & 8.27 & 10.00 \\
\hline & $\mathrm{Sp}, \mu \mathrm{m}$ & 1.82 & 1.54 & 1.43 & 1.47 & 1.33 \\
\hline & Sv, $\mu \mathrm{m}$ & 2.70 & 2.38 & 2.22 & 2.21 & 2.30 \\
\hline & $\mathrm{Sz}, \mu \mathrm{m}$ & 4.52 & 3.92 & 3.65 & 3.68 & 3.63 \\
\hline & $\mathrm{Sa}, \mu \mathrm{m}$ & 0.508 & 0.323 & 0.313 & 0.311 & 0.282 \\
\hline \multirow{3}{*}{$\begin{array}{c}\text { Spatial } \\
\text { parameters }\end{array}$} & Sal, mm & 0.2220 & 0.0160 & 0.0160 & 0.0153 & 0.0160 \\
\hline & Str & 0.3250 & 0.0247 & 0.0239 & 0.0227 & 0.0241 \\
\hline & Std, ${ }^{\circ}$ & 63.7 & 63.7 & 63.7 & 63.7 & 63.7 \\
\hline \multirow{2}{*}{$\begin{array}{c}\text { Hybrid } \\
\text { parameters }\end{array}$} & Sdq & 0.0772 & 0.0772 & 0.0772 & 0.0772 & 0.0772 \\
\hline & Sdr, \% & 0.296 & 0.295 & 0.295 & 0.295 & 0.295 \\
\hline \multirow{2}{*}{$\begin{array}{l}\text { Feature } \\
\text { parameters }\end{array}$} & Spd, $1 / \mathrm{mm}^{2}$ & 322 & 478 & 544 & 534 & 551 \\
\hline & Spc, $1 / \mathrm{mm}$ & 0.0372 & 0.0348 & 0.0340 & 0.0341 & 0.0340 \\
\hline
\end{tabular}


a)

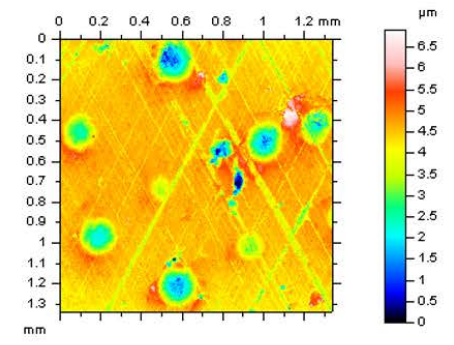

d)

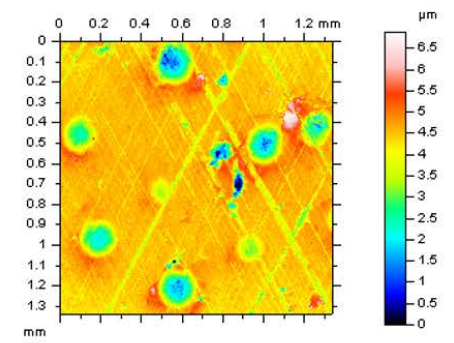

b)

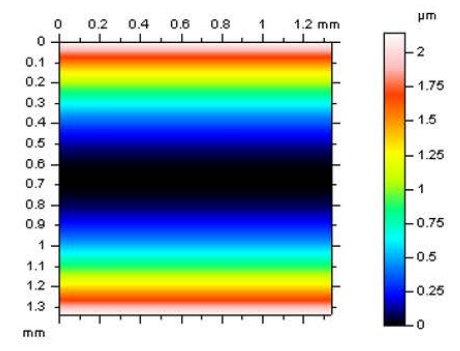

e)

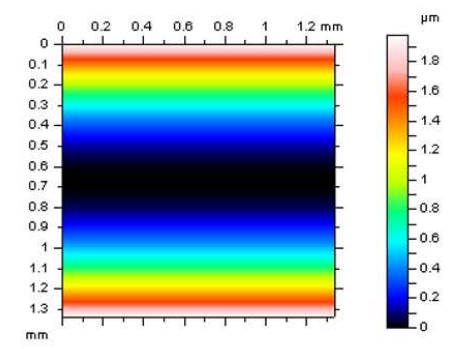

c)

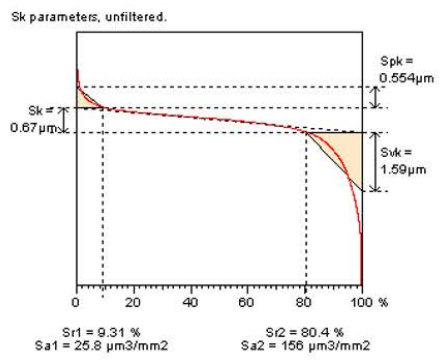

f)

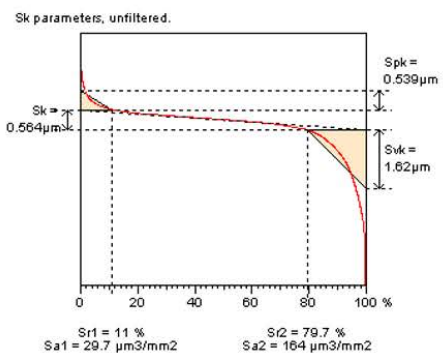

Fig. 4. Surface contour plots (a, d), removed form (b, e) and material ratio curve (c, f) of plateau-honed cylinder liner surface with oil pockets created by burnishing techniques after form removal by: general algorithm of cylinder fitting ( $a, b$ and $c$ ) and cylinder fitted by proposed method (d, e and $f$ )

It was also found that proposed method of cylinder form removal resulted in a decrease of Sk and Spk parameter values by $16 \%$ and $3 \%$ respectively.

The height parameters $\mathrm{Sq}, \mathrm{Sp}, \mathrm{Sv}, \mathrm{Sz}$ and Sa decreased with the proposed procedure but kurtosis Sku and skewness Ssk (equally as for cylinder liners without oil pockets) increased $3 \%$ and $4 \%$ respectively. Spatial parameters
Str and Std did not change or the difference was slight but Sal parameter decreased 3\% (see Table 3). Hybrid parameters (Sdq and $\mathrm{Sdr}$ ) have not changed. Feature parameter Spd increased while peak curvature Spc decreased according to commonly used algorithm of cylinder fitting.

Application of $3^{\text {rd }}$ degree polynomial least square fitted plane caused the following changes

Table 3. Surface topography parameters of plateau-honed cylinder liner with burnished oil pockets for cylinder and polynomial of 3rd degree form removal

\begin{tabular}{|c|c|c|c|c|c|c|}
\hline \multirow{3}{*}{\multicolumn{2}{|c|}{ Parameters }} & \multirow{3}{*}{$\begin{array}{l}\text { Measured } \\
\text { surface }\end{array}$} & \multicolumn{4}{|c|}{ Surface after form removal using: } \\
\hline & & & \multicolumn{2}{|c|}{ cylinder fitted by: } & \multicolumn{2}{|c|}{ polynomial of $3^{\text {rd }}$ degree: } \\
\hline & & & $\begin{array}{l}\text { general algo- } \\
\text { rithm }\end{array}$ & $\begin{array}{c}\text { proposed } \\
\text { method }\end{array}$ & $\begin{array}{c}\text { commonly used } \\
\text { method }\end{array}$ & $\begin{array}{c}\text { proposed algo- } \\
\text { rithm }\end{array}$ \\
\hline \multirow{7}{*}{$\begin{array}{c}\text { Height } \\
\text { parameters }\end{array}$} & $\mathrm{Sq}, \mu \mathrm{m}$ & 0.824 & 0.642 & 0.635 & 0.630 & 0.633 \\
\hline & Ssk & -0.888 & -2.140 & -2.210 & -2.200 & -2.280 \\
\hline & Sku & 5.82 & 10.30 & 10.70 & 10.60 & 10.90 \\
\hline & $\mathrm{Sp}, \mu \mathrm{m}$ & 3.56 & 2.54 & 2.52 & 2.49 & 2.55 \\
\hline & $\mathrm{Sv}, \mu \mathrm{m}$ & 4.94 & 4.36 & 4.35 & 4.30 & 4.36 \\
\hline & $\mathrm{Sz}, \mu \mathrm{m}$ & 8.49 & 6.91 & 6.88 & 6.79 & 6.90 \\
\hline & $\mathrm{Sa}, \mu \mathrm{m}$ & 0.605 & 0.404 & 0.393 & 0.388 & 0.389 \\
\hline \multirow{3}{*}{$\begin{array}{c}\text { Spatial } \\
\text { parameters }\end{array}$} & Sal, mm & 0.2200 & 0.0692 & 0.0672 & 0.0657 & 0.0663 \\
\hline & Str & 0.324 & 0.756 & 0.754 & 0.754 & 0.753 \\
\hline & Std, ${ }^{\circ}$ & 63.4 & 63.4 & 63.4 & 63.4 & 63.4 \\
\hline \multirow{2}{*}{$\begin{array}{c}\text { Hybrid } \\
\text { parameters }\end{array}$} & Sdq & 0.0740 & 0.0739 & 0.0739 & 0.0739 & 0.0739 \\
\hline & Sdr, \% & 0.272 & 0.271 & 0.271 & 0.271 & 0.271 \\
\hline \multirow{2}{*}{$\begin{array}{c}\text { Feature } \\
\text { parameters }\end{array}$} & Spd, $1 / \mathrm{mm}^{2}$ & 81.9 & 153.0 & 156.0 & 165.0 & 159.0 \\
\hline & $\mathrm{Spc}, 1 / \mathrm{mm}$ & 0.0764 & 0.0633 & 0.0630 & 0.0617 & 0.0626 \\
\hline
\end{tabular}


a)

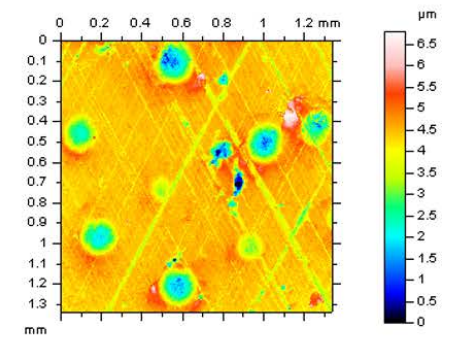

d)

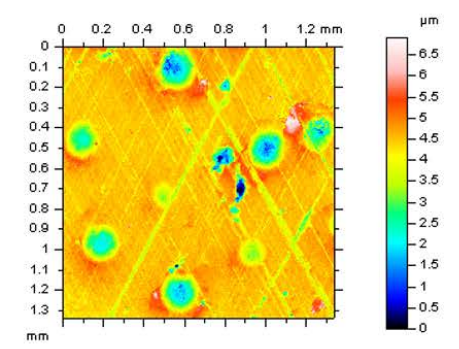

b)

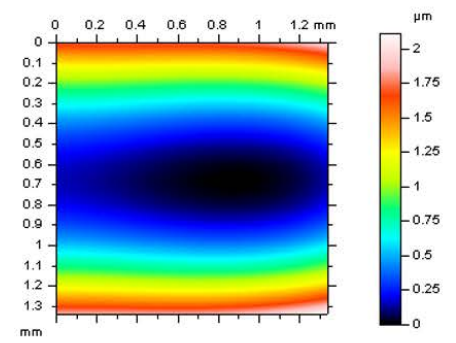

e)

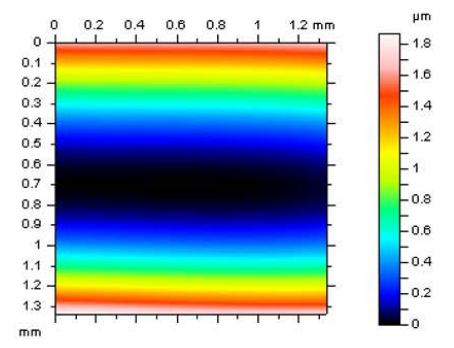

c)

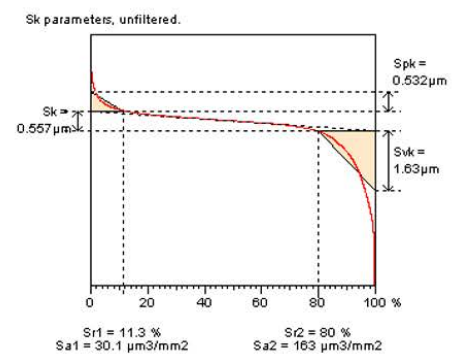

f)

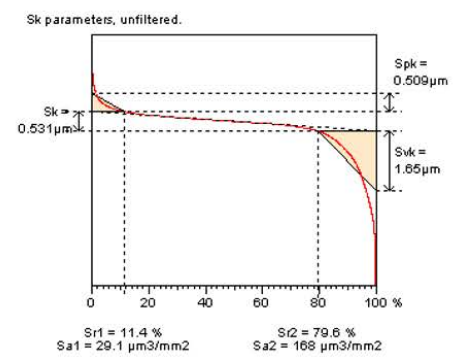

Fig. 5. Contour plots of surface after form removal (a, d); removed form (b, e); material ratio curve (c, f) of cylinder liner after plateau-honing process with additionally added oil pockets and after form removal by 3rd degree of polynomial fitted by algorithm: generally used ( $a, b$ and $c)$, proposed (d, e and f)

(according to generally used procedure) of parameters values: decrease of Sk and Spk parameters when Svk parameter increased (see Figure $5 \mathrm{c}$ and $5 \mathrm{f}$ ).

It was similar for plateau-honed cylinder liners that usage of the least square fitted polynomial plane resulted in increasing Sq, Ssk, Sku and Sv parameters. For cylinder liners containing additionally burnished dimples $\mathrm{Sp}, \mathrm{Sz}$ and $\mathrm{Sa}$ parameters also increased (Table 3 ). The difference in values of spatial parameters Str and Std was negligible or equal to zero. Sal parameter increased in contrast to the plateau-honed cylinder liners. Hybrid parameters (Sdq, Sdr) have not changed repeatedly (to compare see Table 2 and Table 3). For feature parameters peak density Spd decreased 4\% and peak curvature Spc increased from 1 to $2 \%$.

Table 4. Surface topography parameters of plateau-honed cylinder liner with additionally burnished oil pockets for various form removal

\begin{tabular}{|c|c|c|c|c|c|c|c|}
\hline \multirow{3}{*}{\multicolumn{2}{|c|}{ Parameters }} & \multirow{4}{*}{$\begin{array}{c}\begin{array}{c}\text { Measured } \\
\text { surface }\end{array} \\
0.824\end{array}$} & \multicolumn{5}{|c|}{ Surface after form removal using: } \\
\hline & & & \multicolumn{2}{|c|}{ proposed procedure of: } & \multirow{3}{*}{$\begin{array}{c}\text { Gaussian filter } \\
0.620\end{array}$} & \multirow{3}{*}{$\begin{array}{c}\begin{array}{c}\text { Gaussian re- } \\
\text { gression filter }\end{array} \\
0.600\end{array}$} & \multirow{3}{*}{$\begin{array}{c}\begin{array}{c}\text { robust Gaussian } \\
\text { regression filter }\end{array} \\
0.638\end{array}$} \\
\hline & & & \multirow{2}{*}{$\begin{array}{c}\begin{array}{c}\text { cylinder } \\
\text { fitting }\end{array} \\
0.635\end{array}$} & \multirow{2}{*}{$\begin{array}{c}\begin{array}{c}\text { polynomial of } \\
3^{\text {rd }} \text { degree }\end{array} \\
0.633\end{array}$} & & & \\
\hline \multirow{7}{*}{$\begin{array}{c}\text { Height } \\
\text { parameters }\end{array}$} & $\mathrm{Sq}, \mu \mathrm{m}$ & & & & & & \\
\hline & Ssk & -0.888 & -2.210 & -2.280 & -1.840 & -2.140 & -2.360 \\
\hline & Sku & 5.82 & 10.70 & 10.90 & 9.67 & 10.70 & 11.10 \\
\hline & $\mathrm{Sp}, \mu \mathrm{m}$ & 3.56 & 2.52 & 2.55 & 2.79 & 2.46 & 2.60 \\
\hline & Sv, $\mu \mathrm{m}$ & 4.94 & 4.35 & 4.36 & 4.31 & 4.20 & 4.36 \\
\hline & $\mathrm{Sz}, \mu \mathrm{m}$ & 8.49 & 6.88 & 6.90 & 7.10 & 6.67 & 6.97 \\
\hline & $\mathrm{Sa}, \mu \mathrm{m}$ & 0.605 & 0.393 & 0.389 & 0.379 & 0.362 & 0.392 \\
\hline \multirow{3}{*}{$\begin{array}{c}\text { Spatial } \\
\text { parameters }\end{array}$} & Sal, mm & 0.2200 & 0.0672 & 0.0663 & 0.0662 & 0.0630 & 0.0680 \\
\hline & Str & 0.324 & 0.754 & 0.753 & 0.772 & 0.744 & 0.753 \\
\hline & Std, ${ }^{\circ}$ & 63.4 & 63.4 & 63.4 & 63.4 & 63.4 & 63.4 \\
\hline \multirow{2}{*}{$\begin{array}{c}\text { Hybrid } \\
\text { parameters }\end{array}$} & Sdq & 0.0740 & 0.0739 & 0.0739 & 0.0583 & 0.0491 & 0.0739 \\
\hline & Sdr, \% & 0.272 & 0.271 & 0.271 & 0.169 & 0.120 & 0.271 \\
\hline \multirow{2}{*}{$\begin{array}{c}\text { Feature } \\
\text { parameters }\end{array}$} & $\mathrm{Spd}, 1 / \mathrm{mm}^{2}$ & 81.9 & 156.0 & 159.0 & 70.2 & 52.9 & 154.0 \\
\hline & Spc, $1 / \mathrm{mm}$ & 0.0764 & 0.0630 & 0.0626 & 0.0430 & 0.0285 & 0.0628 \\
\hline
\end{tabular}


a)

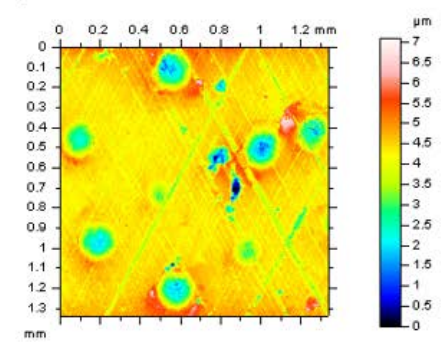

d)

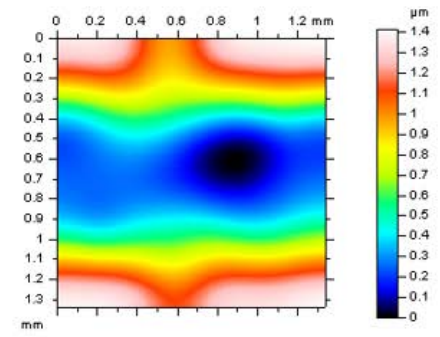

g)

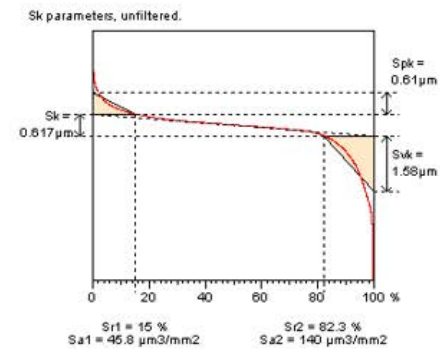

b)

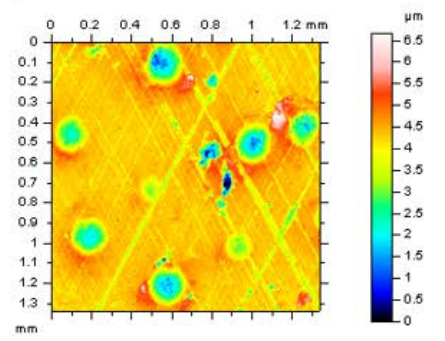

e)

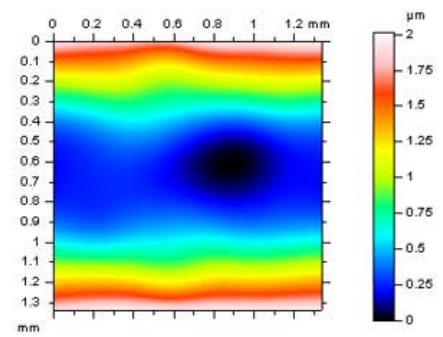

h)

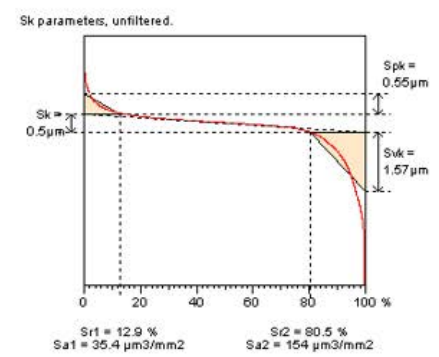

c)

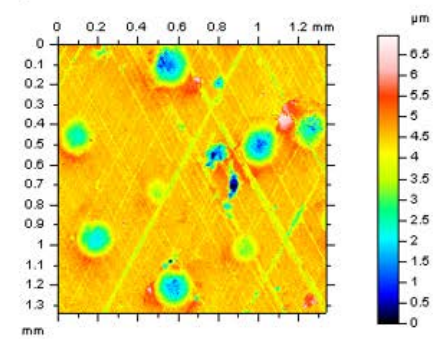

f)

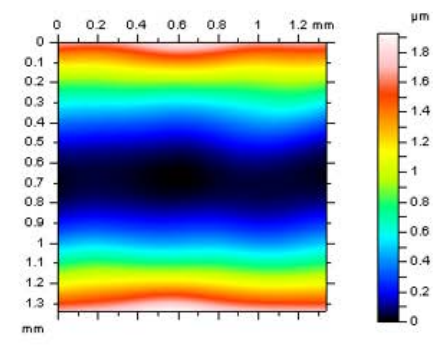

i)

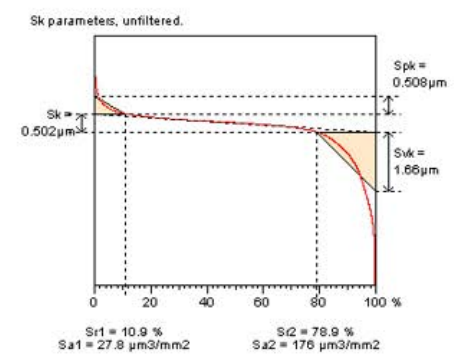

Fig. 6. Surface contour plots of plateau-honed cylinder liner with additionally added oil pockets after form removal ( $a, b$ and c), removed form ( $d$, e and f) and material ratio curve ( $g$, h and i) obtained by: Gaussian filter (a, d and $\mathrm{g}$ ), Gaussian regression filter (b, e and h) and robust Gaussian regression filter (c, f and i); cut-off equal to $0.8 \mathrm{~mm}$

For plateau-honed cylinder liners with added oil pockets, robust filters are recommended. Proposed least square procedures were compared with various Gaussian filtering (general Gaussian filter, Gaussian regression filter and robust Gaussian filter) for fitting the best reference plane. The difference of various Gaussian filtering (with $\lambda \mathrm{c}$ equal to $0.8 \mathrm{~mm}$ ) was showed in Figure 6. It was obvious that regression filter gave better results in the edge-filtering than regular Gaussian filter. Moreover, application of robust filter caused a smaller distortion of surface topography parameters according to oil pockets occurrence.

Generally used Gaussian filter did not allow to remove form properly. The edge-filtering problems were not solved and the reference plane was falsely estimated. Better results were obtained when regression filter was applied. Core roughness Sk parameter has reached the minimum value after regression filtering but difference according to robust filtering was very small about $0.4 \%$ (see Figure 6h and 6i). However, the value of re- duced summit height Spk parameter was higher for regression filter about $7.5 \%$ due to robust filtering results.

It was found that reference planes obtained by regular Gaussian filter and regression filtering were wrong approximated when oil pockets and deep valleys were located close to each other (see Figure 6e). Moreover, the minor difference of Spk parameter values was received after robust filtering and application of $2^{\text {nd }}$ degree of polynomial (to compare see Figure $5 \mathrm{f}$ and 6i). Slight variation was also found for feature parameters (Table 4) but for hybrid parameters difference was not noticed. The values of some spatial parameters (Str and Std) were similar after application of proposed polynomial fitting procedure according to robust filtering, but the value of auto-correlation length parameter (Sal) was bigger.

It was found that selection of reference planes by Gaussian filter and regression filtering can cause wrong estimation of dimple sizes. For height parameters, the differences of values 
Table 5. Surface topography parameters of turned piston skirt after form removal by the 3rd and 4th degree of polynomial

\begin{tabular}{|c|c|c|c|c|c|c|}
\hline \multirow{3}{*}{\multicolumn{2}{|c|}{ Parameters }} & \multirow{3}{*}{$\begin{array}{l}\text { Measured } \\
\text { surface }\end{array}$} & \multicolumn{4}{|c|}{ Surface after form removal using: } \\
\hline & & & \multicolumn{2}{|c|}{$\begin{array}{l}\text { polynomial of 3rd degree } \\
\text { fitted by: }\end{array}$} & \multicolumn{2}{|c|}{$\begin{array}{l}\text { polynomial of } 4 \text { th degree } \\
\text { fitted by: }\end{array}$} \\
\hline & & & $\begin{array}{l}\text { general algo- } \\
\text { rithm }\end{array}$ & $\begin{array}{l}\text { proposed } \\
\text { method }\end{array}$ & $\begin{array}{l}\text { commonly used } \\
\text { method }\end{array}$ & $\begin{array}{l}\text { proposed algo- } \\
\text { rithm }\end{array}$ \\
\hline \multirow{7}{*}{$\begin{array}{c}\text { Height } \\
\text { parameters }\end{array}$} & $\mathrm{Sq}, \mu \mathrm{m}$ & 5.27 & 4.19 & 4.21 & 4.14 & 4.20 \\
\hline & Ssk & -0.112 & 0.270 & 0.186 & 0.248 & 0.294 \\
\hline & Sku & 2.56 & 1.77 & 1.70 & 1.76 & 1.72 \\
\hline & $\mathrm{Sp}, \mu \mathrm{m}$ & 12.7 & 11.5 & 11.8 & 11.4 & 11.3 \\
\hline & $\mathrm{Sv}, \mu \mathrm{m}$ & 18.1 & 12.1 & 11.9 & 12.8 & 12.1 \\
\hline & $\mathrm{Sz}, \mu \mathrm{m}$ & 30.9 & 23.7 & 23.6 & 24.2 & 23.4 \\
\hline & $\mathrm{Sa}, \mu \mathrm{m}$ & 4.28 & 3.69 & 3.73 & 3.64 & 3.72 \\
\hline \multirow{3}{*}{$\begin{array}{c}\text { Spatial } \\
\text { parameters }\end{array}$} & Sal, mm & 0.0705 & 0.0509 & 0.0509 & 0.0470 & 0.0509 \\
\hline & Str & 0.0922 & 0.0546 & 0.0546 & 0.0504 & 0.0546 \\
\hline & Std, ${ }^{\circ}$ & 90 & 90 & 90 & 90 & 90 \\
\hline \multirow{2}{*}{$\begin{array}{c}\text { Hybrid } \\
\text { parameters }\end{array}$} & Sdq & 0.132 & 0.131 & 0.131 & 0.131 & 0.131 \\
\hline & Sdr, \% & 0.859 & 0.848 & 0.848 & 0.849 & 0.848 \\
\hline \multirow{2}{*}{$\begin{array}{c}\text { Feature } \\
\text { parameters }\end{array}$} & $\mathrm{Spd}, 1 / \mathrm{mm}^{2}$ & 4.00 & 9.00 & 9.00 & 8.75 & 9.00 \\
\hline & $\mathrm{Spc}, 1 / \mathrm{mm}$ & 0.0362 & 0.0250 & 0.0246 & 0.0252 & 0.0257 \\
\hline
\end{tabular}

were larger for Gaussian filter and regression filter in accordance with proposed procedures and robust filter.

\section{Turned piston skirts}

Application of least square fitted cylinder plane in areal form removal gave similar results as commonly used cylinder algorithm. Usage the Gaussian filtering methods (regular Gaussian filter, regression filtering and robust filter) have not given desired results. It was suggested to compare the commonly used polynomial approximation method with proposed procedure of least square polynomial fittings.

It was noticed (Figure $7 \mathrm{a}$ and $7 \mathrm{~d}$ ) that proposed procedure for $4^{\text {th }}$ degree of polynomial gave better results in the edges of analysed surface (form was removed more effectively). The distortion of Sk parameter (expressed in percentage) was smaller than Spk and Svk parameters (see Figure $7 \mathrm{c}$ and $7 \mathrm{f}$ ).

For $3^{\text {rd }}$ degree of polynomial fitted by proposed procedure, the height parameters skewness Ssk and maximum peak height $\mathrm{Sp}$, were severely distorted in accordance with polynomial of $4^{\text {th }}$ degree (see Table 5). Higher degree ( $\left.4^{\text {th }}\right)$ of polynomial gave better results in Sk group parameters analysis (Figure 7c and 7f). For proposed procedure Sk parameter decreased.
For each type of reference plane $\left(3^{\text {rd }}\right.$ or $4^{\text {th }}$ degree of polynomial approximation) all height parameters decreased except the skewness parameter Ssk according to the measured surface. From spatial parameters Std was not changed but Sal and Str decreased. For both types of $3^{\text {rd }}$ degree polynomial approximation and for the 4th degree of least square fitted polynomial plane, the resulting values of auto-correlation length and texture-aspect ratio parameters were constant, but for generally used $4^{\text {th }}$ degree of polynomial the values were smaller by about $8 \%$. Hybrid parameters Sdq and Sdr were constant for all the reference plane suggested.

Peak curvature Spc parameter increased when the degree of polynomial increased also. The value of peak density Spd parameter was invariable except generally applied polynomial of 4th degree.

For piston skirt surfaces it is recommended to select the reference plane by application of 4 th degree of polynomial plane fitted by the proposed method. In some cases the surface topography filtering of piston skirts is more edge-selected when the least square procedure is applied.

\section{CONCLUSIONS}

1. Selection of reference plane by application of the least square cylinder fitting procedure 
a)

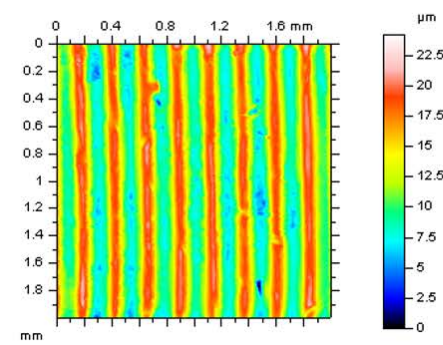

d)

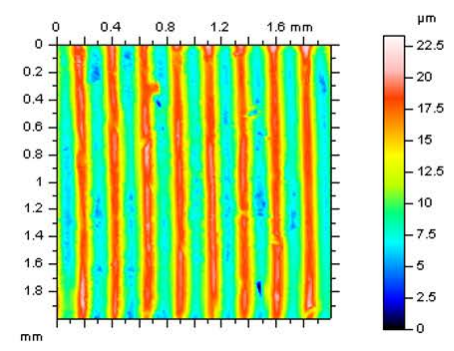

b)

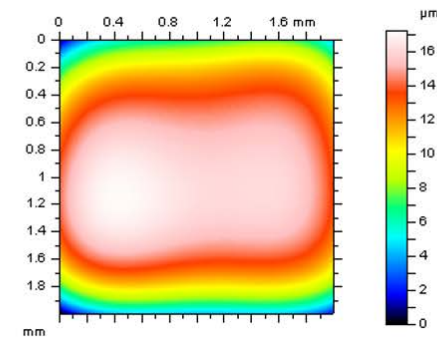

e)

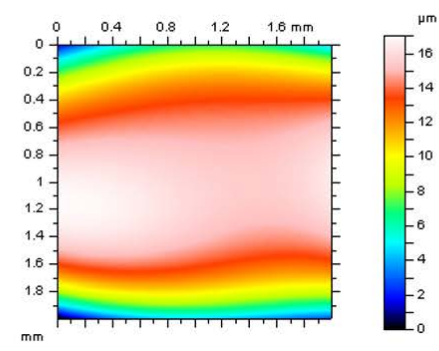

c)

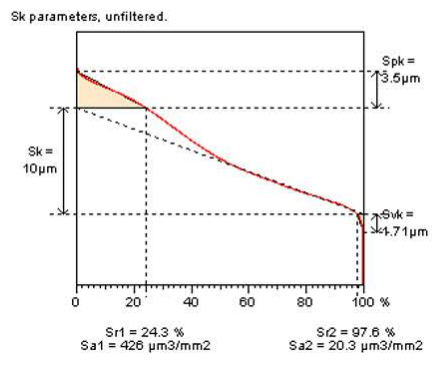

f)

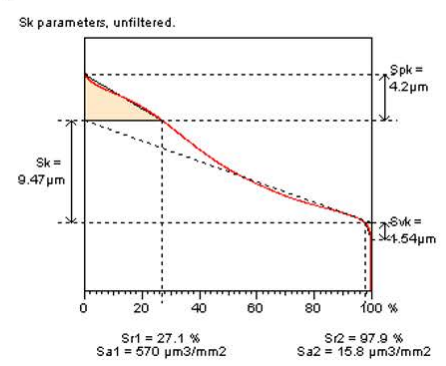

Fig. 7. Contour plots of surface after form removal (a, d); removed form (b, e); material ratio curve (c, f) of turned piston skirt surface after form removal obtained by 4th degree of polynomial fitted by: generally used algorithm (a, b and c), proposed procedure (d, e and f)

gave better results for both types of cylinder liners (after plateau-honing and plateau-honed with additionally added oil pockets). For piston skirt surfaces obtained results were very similar for commonly used algorithm.

2. Applying of polynomial least square fitting method for all three types of surfaces provided a noticeable improvement. For piston skirt surfaces this method gave usually better edgeresults in surface topography form removal. For cylinder liners, this technique provided higher robustness for valley occurrence.

3. According to Gaussian filter and Gaussian regression filter, polynomial least square fitting algorithm improved encouraging results. However, proposed procedure brought negligible effects for all three types of measured parts due to robust Gaussian regression filter.

4. It is suggested to select the reference plane along with surface topography parameters analysis. Least square fitting methods not always gave better results due to minimization of the distortion of parameter values. For proper selection of reference plane, the Sk parameters should be mandatory analyzed.

5. For further research robust Gaussian regression filter as well as polynomial least-square fitting method are recommended for areal form removal in surface topography measure- ment. It is substantial to select the reference plane by these two methods instead of ordinary Gaussian filtering.

\section{Acknowledgements}

This paper was prepared with financial support from the project no. 2013/09/N/ST8/04333 from National Science Center.

\section{REFERENCES}

1. Brinkman S., Bodschwinna H.: Advanced Gaussian Filters in Advanced Techniques for Assessment Surface Topography, Elsevier, 2000.

2. Brinkmann S., Bodschwinna H., Lemke H.-W.: Accessing roughness in three-dimensions using Gaussian regression filtering, International Journal of Machine Tools \& Manufacture 41, 2001, 2153-2161.

3. De Chiffre L., Lonardo P., Trumpold H., Lucca D.A., Goch G., Brown C.A., Raja J., Hansen H.N.: Quantitative Characterisation of Surface Texture, CIRP Annals - Manufacturing Technology, 2000 2, 635-642, 644-652.

4. Dobrzański P., Pawlus P.: Digital filtering of surface topography Part I. Separation of one-process surface roughness and waviness. Precision Engineering 34, 2010, 647-650.

5. Dobrzański P., Pawlus P.: Digital filtering of surface topography: Part II. Applications of robust and 
valley suppression filters. Precision Engineering 34, 2010, 651-658.

6. Dobrzański P., Pawlus P.: Modification of robust filtering of stratified surface topography. Metrology and Measurement Systems 20 (1), 2013, 107-118.

7. Forbes A.B.: Areal form removal in: Characterisation of Areal Surface Texture, Springer 2013, 107-128.

8. Forbes A.B.: Least squares best fit geometric elements, NLP report DITC 40 (89), Teddington, UK, 1989.

9. Grabon W., Pawlus P., Galda L., Dzierwa A., Podulka P.: Problems of surface topography with oil pockets analysis, Journal of Physics: Conference Series, 2011, 311012023.

10. Janecki D.: Gaussian filters with profile extrapolation, Precision Engineering 4, 2011, 602-606.

11. Lou S., Jiang X., Scott P.J.: Applications of morphological operations in surface metrology and dimensional metrology. Journal of Physics: Conference Series, 2014, 483012020.

12. Mainsah E., Greenwood J. A., Chetwynd D. G.: Metrology and Properties of Engineering Surfaces, Springer, 2001.

13. Muralikrishnan B., Raja J.: Computational surface and roundness metrology, Springer, 2009.

14. Pawlus, P.: A study on the functional properties of honed cylinder surface during running-in. Wear, $176,1994,247-254$

15. Pawlus, P.: Effects of honed cylinder surface topography on the wear of piston-piston ring-cylinder assemblies under artificially increased dustiness conditions. Tribology International, 26, 1993, 49-56.

16. Pawlus, P.: The errors of surface topography measurement using stylus instruments. Metrology and Measurement Systems, 3, 2002, 273-289.

17. Pawlus P., Reizer R., Podulka P., Dobrzanski P.: Comparison of surface topography measurements obtained with optical and stylus methods, Proc. of $\mathrm{XI}^{\text {th }}$ Intern. Scientific Conference on Coordinate Measuring Technique CMT 2014, Bielsko Biała, 124-130.

18. Podulka P., Dobrzański P., Pawlus P.: Selection of reference plane by application of robust Gaussian regression filter of $\mathrm{n}$-th orders. In: 5 th International Conference on Surface Metrology, 4th-7th April 2016, Poznań, Poland.

19. Podulka P., Dobrzanski P., Pawlus P., Lenart A.: The effect of reference plane on values of areal surface topography parameters from cylindrical elements, Metrology and measurement systems, 2, 2014, 247-256.

20. Podulka P., Pawlus P., Dobrzanski P., Lenart A.: Spikes removal in Surface measurement, Journal of Physics: Conference Series, 2014, 483012025.

21. Podulka P., Pawlus P., Dobrzański P., Reizer R.: Areal form removal by cylinder fitting, Proceedings of XIth International Scientific Conference on Coordinate Measuring Technique CMT 2014, Bielsko Biała, 145-149.

22. Press P.H., Teukolski S.A., Wetterling W.T., Flannery B.P.: Nemerical Recipes. Cambridge University Press, Cambridge, 1992.

23. Rosen B-G., Anderberg C., Ohlsson R.: Parameter correlation study of cylinder liner roughness for production and quality control. Proceedings of the Institution of Mechanical Engineers, Part B: Journal of Engineering Manufacture, 222, 2008, 1475- 1487.

24. Sullivan P.J.: Surface topography filtering in: Metrology and Properties of Engineering Surfaces, Springer, 2001.

25. Stout K.J., Sullivan P.J., Dong W.P., Mainsah E., Luo N., Mathia T., Zahouani H.: The development of methods for the characterisation of roughness in three dimensions. Publication EUR 15178 EN Commission of the European Communities, 1993.

26. Whitehouse D.J.: Handbook of Surface and Nanometrology, CRC Press, 2010.

27. Yuan Y.-B., Qiang X.-F., Song J.-F., Vorburger T.V.: A fast algorithm for determining the Gaussian filtered mean line in surface metrology, Precision Engineering, 1, 2000, 62-69.

28. Yuan Y.-B, Piao W.-Y., Xu J.-B.: A fast Gaussian filtering algorithm for three-dimensional surface roughness measurements, Journal of Physics: Conference Series, 2006, 48 1401-1406.

29. Zeng W., Jiang X., Scott P.: A generalised linear and nonlinear spline filter, 271, 2011, 544-547. 